\title{
Yoğun Bakım Ünitelerinde Koruyucu Hasta Pozisyonları, Egzersiz ve Mobilizasyon: Güvenli Uygulama Rehberi
}

\author{
Preventive Patient Position, Exercises and Mobility in Intensive Care Units: \\ Safe Practice Guidelines
}

\author{
Funda BÜYÜKYILMAZ¹, Aysel ÖZSABAN²
}

İletişim/ Correspondence: Funda Büyükyılmaz Adres / Adress: İ.Ü. Florence Nightingale Hemşirelik Fakültesi, Abide-i Hürriyet Cad. 34381 Şişli/ İstanbul, Tel: 021244000 00/27119 Fax: 02122244990 E-mail: feyilmaz@istanbul.edu.tr

\begin{abstract}
$\ddot{O} Z$
Yoğun bakım ünitelerinde güvenli hasta pozisyonlarl, egzersiz ve mobilizasyon sılklıla uygulanan hemşirelik girişimlerindendir. Sik aralıklarla pozisyon değiştirme, egzersiz ve mobilizasyon uygulamanın amacl; vücudun normal duruşunu sürdürmek, etkilenen vücut bölgelerinde basıncı azaltmak, hastanın rahatlı̆̆ını sağlamak, pulmoner sekresyonların azaltılmasına yardımcı olmak ve oksijen satürasyonunu olumlu düzeyde etkilemektir. Bu doğrultuda, bu makalede; yoğun bakım ortamlarında sıklıkla uygulanan hemşirelik girişimleri arasında yer alan güvenli-koruyucu hasta pozisyonlarl, egzersiz ve mobilizasyona ilişkin anahtar noktalar ve konu ile ilgili literatür sonuçları açıklanarak uygulamalara rehberlik etmek amaçlandı.
\end{abstract}

Anahtar Kelimeler: Hasta pozisyonları, egzersiz, mobilizasyon, yoğun bakım ünitesi.

\section{ABSTRACT}

Safety patient position, exercises and mobility are frequently implemented nursing interventions in intensive care units. The aim of the changing position, implementing exercises and mobility to maintain normal body posture reduces the pressure on the affected body parts ensures patients' comfort, reduce pulmonary secretion and improve blood oxygenation. In this context, this article are written for guidance for nurses that explain key points and literature results in changing position, exercises and mobility implemented frequently nursing interventions.

Keywords: Patients position, exercises, mobility, intensive care unit.

\section{Giriş}

Yoğun bakım ünitelerinde hasta pozisyonları, egzersiz ve erken aşamalı mobilizasyon oldukça önemli uygulamalardır. Pozisyon değişimi ile yeterli ventilasyon/ perfüzyon dengesi sağlanarak solunum komplikasyonları önlenirken, etkilenen vücut bölgelerinin desteklenmesi ile kas-iskelet sistemine özgü sorunlar önemli ölçüde azaltılabilmektedir. Egzersiz uygulaması ile hastada güç kaybı, atrofi-kontraktür ve derin ven trombozu (DVT) riski azalt1larak erken mobilizasyona olanak sağlanabilmektedir (Clark, Lowman, Griffin, Matthews ve Reiff 2013). Bu konu ile ilgili olarak Morris (2007), yoğun bakım ortamında yatan hastalarda uzun süren hareketsizlik sonucunda duygu durum değişiklikleri, güç kaybı, solunum sistemine ilişkin sorunların yanı sıra uzayan dönemlerde, özellikle 1 haftanın sonunda, ciddi ve kalıcı nöromusküler sorunların da geliştiğini vurgulamaktadır.

${ }^{1}$ Doç. Dr. İstanbul Üniversitesi Florence Nightingale Hemşirelik Fakültesi, ${ }^{2}$ Arş. Gör. Dr. İstanbul Üniversitesi Florence Nightingale Hemşirelik Fakültesi Yazının gönderilme tarihi: 04.01.2016 
Benzer şekilde Fan, Zanni, Dennison, Lepre ve Needham (2009) yoğun bakım hastalarında uzun süreli hareketsizliğin / uzayan yatak istirahatinin özellikle alt ekstremite kaslarında protein sentezini azaltarak güç kaybına neden olduğunu belirtmektedir. Tüm bu nedenler hastanın rahatlık / konfor düzeyini olumsuz ölçüde etkilerken; aynı zamanda iyileşmenin gecikmesine, yatış süresinin uzamasına, bakım ve tedavi giderlerinin artmasına da yol açabilmektedir (İnce 2006; Korkut 2011; Kuyurtar 2010; Y1ldırım ve Yavuz 2009).

$\mathrm{Bu}$ doğrultuda bu makale ile yoğun bakım ünitelerinde sıklıkla uygulanan hemşirelik girişimlerinden olan güvenli hasta pozisyonları, egzersiz ve erken aşamalı mobilizasyona ilişkin anahtar noktalar ve konu ile ilgili literatür sonuçları açıklanarak, hemşirelere rehberlik etmesi amaçlandi.

\section{Yoğun Bakım Ünitelerinde Güvenli Hasta Pozisyonları}

Yoğun bakım ünitelerinde güvenli hasta pozisyonları sıklıkla uygulanan hemşirelik girişimlerindendir. S1k aralıklarla pozisyon değiştirmenin amacı; vücudun normal duruşunu sürdürmek, etkilenen vücut bölgelerinde basıncı azaltmak, atrofi-kontraktür oluşumunu engellemek, hastanın rahatlığını sağlamak, pulmoner sekresyonların azaltılmasına yardımcı olmak ve kandaki ventilasyon-perfüzyon uyumunu iyileştirerek oksijen konsantrasyonunu artırmaktır (Korkut 2011; Kuyurtar 2010; Yıldırım ve Yavuz 2009).

Normal vücut duruşu; bedenin değişik pozisyonlarında eklemlerin, tendonların ve ligamentlerin doğal yapısının korunduğu durumu belirtir. Anatomik pozisyona uygun duruş/yatış sırasında vücut bölümleri arasında zorlanma olmaz (Korkut 2011; Yıldırım ve Yavuz 2009). Ancak hastanın uzun süre aynı pozisyonda kalması, vücut ağırlığının kemik çıkıntılar üzerine yoğunlaşmasına ve bu ağırlığın eşit şekilde dağılmaması nedeniyle altta kalan bölgelerin basınçtan etkilenmesine yol açabilmektedir. Bu basınç uzun süreli olduğunda ise; deride bozulma/ basınç yarası riski artmaktadır (Beğer 2004; Şendir, Büyükyılmaz ve Aktaş 2012; Şendir 2005). Bununla birlikte sürekli aynı pozisyonda yatmak pulmoner sekresyonların birikmesine, hastanın hastalığı dışında zaman zaman yaşamını tehdit edebilecek düzeyde ilave komplikasyonlar yaşamasına neden olmaktadır.

$\mathrm{Bu}$ bağlamda yoğun bakım ünitelerinde vücudun normal duruşunu sürdürmek ve hareketsizliğe bağlı komplikasyonları önlemek için sıklıkla sırt üstü (supine), yüz üstü (prone), yan yatış (lateral), yarı oturur/oturur (semi fawler/ fawler) pozisyonları bireyin durumuna göre tercih edilmektedir (Acaroğlu 2011; Korkut 2011; Y1ldırım ve Yavuz 2009).

Sırt üstü (supine) yatış pozisyonu: Kolların gövdenin iki yanında olduğu, bacakların düz uzatıldığı, sırt üstü yatış şeklidir. İnce bir yastık ile başının altı desteklenebilir. Bu pozisyonda özellikle basınç altında kalan boyun ve bel omurları ile dizlerin altı desteklenmelidir. Ayak düşmesini önlemek için ayak tabanına destek konulmalıdır. Bu pozisyonda uzun süre kalan hastalarda özellikle altta kalan vücut bölümleri basınçtan etkilenmekte ve pulmoner komplikasyonlar görülebilmektedir (Dillon 2007; Kuyurtar 2010; Tritak 2009). Supine pozisyonunda yatan bir hastanın akciğer kapasitesi, karın içi organlarının diyafragmaya olan basıncı nedeniyle azaldığından, dokuların oksijenlenmesi de azalır. $\mathrm{Bu}$ nedenlerden dolayı supine pozisyonunda uzun süre yatan hastalarda atelektazi ve pnömoniye yatkınlık artar (Yıldırım ve Yavuz 2009). Benzer şekilde Clini ve Ambrosino (2005)'da supine pozisyonunun, mekanik ventilasyonda olan hastalarda, mide içeriği aspirasyonunu ve nazokomiyal infeksiyon riskini arttırdığını belirtmektedir. İnce (2006) yoğun bakım ünitelerinde, hastaların sıklıkla supine pozisyonunda izlendiğini, bu pozisyonda uzun süre kalınd1ğında, akciğer volümünde azalma meydana geldiğini, sekresyonların, aspire edilen mide içeriği ve hücre dış1 interstisyel sıvıların akciğerin dokusunda biriktiğini belirtmektedir. Bununla birlikte, hastanın supine pozisyondan lateral veya prone pozisyona döndürülmesinin, akciğer volümü (fonksiyonel reziduel kapasite) ve oksijenasyonda belirgin artışla sonuçlandığını vurgulamaktadır. Bu konu ile ilgili Winlekman (2000), 
kafa travması geçiren hastalarda yatak başının 30 derece yükseltilmesinin kafa içi basıncı düşürdüğünü ve serebral kan akımını arttırdığını belirtmektedir. Yıld1rım ve Yavuz (2010) yatak başının 30 ve 45 dereceye yükseltildiği sirtüstü pozisyonlarda elde edilen hemodinamik ölçüm sonuçlarının, sırtüstü 0 derece pozisyonda elde edilen basınç ölçüm sonuçları ile benzer olduğunu ve hemodinamik ölçümlerin yatak başının tamamen düzleştirilmeden de güvenli bir şekilde yapılabileceğini saptamışlardır.

Yüzüstü (prone) yatıs pozisyonu: Hastanın ellerini başının altına koyarak başını çevirip yüzüstü yatmasıdır. Alt bacaklara ve kadınlarda gögüs altına ince bir destek konulabilir. Rahat bir uyku pozisyonudur (Dillon 2007; Tritak 2009). Bu pozisyon basınç yarası riskini azaltarak, doku oksijenasyonunu artırarak akciğer infeksiyonu riskini azaltır (Bloomfield ve ark. 2009). Bununla birlikte Clini ve Ambrosino (2005)'nun literatür inceleme çalışmasında; akut solunum zorlugu (acute respiratory distress syndrome-ARDS) olan hastalarda prone pozisyonunun ventilasyon-perfüzyon oranını dengeleyerek ödemi azalttığı ve fonksiyonel rezidüel kapasiteyi arttırdığı belirtilmektedir.

Yan (lateral) yatıs pozisyonu: Hastanın sağ ya da sol tarafına döndürülerek yan yatırılmasıdır. Baş, skapula, sakrum ve topuk gibi kemik çıkıntılar basınçtan etkilenmez. Bacaklar ve ayaklar destek kullanılmaksizın hafif fleksiyon durumundadır. Sakıncası, altta kalan vücut bölümlerinin desteklenememesidir (Dillon 2007; Tritak 2009). Hasta lateral pozisyona getirildiğinde, altta kalan akciğerde dolaşım artarken, üst tarafta kalan akciğerde dolaşım azalması söz konusu olacaktır (Clini ve Ambrosino 2005; Yıldırım ve Yavuz 2009). Ancak son y1llarda, akciğer ekspansiyonunun sağlanması, oksijenasyonun arttırılması ve sekresyon birikiminin önlenmesi amaciyla kinetik terapi (sürekli lateral rotasyonel tedavi) uygulamasının kullanımı gündeme gelmiştir. Kinetik terapi, hastanın yatağın uzun ekseni boyunca $\geq 40$ derecelik açıda her iki yan tarafa yavaş ve sürekli olarak döndürülmesidir (İnce 2006). Bu konu ile ilgili yapılan çalışmalar incelendiğinde; Banasik ve Emerson (2001) yoğun bakım ünitesinde yatan hastalarda doku oksijenlenmesinde üç farklı pozisyonun (supine, sağ ve sol lateral) etkisini incelmiş ve her pozisyon değişiminden $15 \mathrm{dk}$. sonra oksijen satürasyonunu $\left(\mathrm{SaO}_{2}\right)$ ölçmüşlerdir. Çalışmada ilk 3-5 dk. içinde $\mathrm{SaO}_{2}$ değerinde geçici düşme saptanmış, 3-5 dk. içinde normal $\mathrm{SaO}_{2}$ değerine dönemeyen ve oksijen desteği alan hastaların lateral pozisyonu tolere edemediğini belirtmişlerdir. Tonyoo, Vilaichone ve Permpikul (2006)'un çalışmasında ise; akut solunum sıkıntısı olan (ARDS) hastaların sağ, sol lateral ve supine pozisyonunda oksijenlenme durumlarını karşılaştırmıştır. Sağ lateral pozisyonun $\mathrm{PaO}_{2}$ değerini olumlu ölçüde arttırdığını saptamışlardır. Thomas, Paratz, Pilmann ve Stanton (2007) ise, yoğun bakım ünitesinde ventilasyon desteği alan ve akciğer sorunu olan ve olmayan hastaların $30 \mathrm{dk}$. supine, $120 \mathrm{dk}$. lateral ve $30 \mathrm{dk}$. supine pozisyonu sirasında hemodinamik değerlerini incelemişlerdir. Hemodinamik değerleri stabil olan ve ventilasyonla desteklenen hastaların, lateral pozisyonu iyi tolere edebildiğini saptamışlardır.

\section{Yarı otururfoturur (semifawler/fawler) yatış pozis-} yonu: Oturur pozisyon; yatak başucunun 90 derece yükseltilerek, alt bacaktaki dolaşımı engellemeyecek şekilde dizlerin hafifçe desteklenmesidir. Yatak baş1nın 45-60 derece yükseltilmesi ise yarı oturur (semifawler) pozisyon olarak isimlendirilir. Kalça ve diz eklemleri normal vücut duruşunu sürdürecek şekilde desteklenmelidir (Dillon 2007; Tritak 2009). Clini ve Ambrosino (2005), fawler pozisyonun akciğer kapasitesini olumlu ölçüde desteklediğini belirtmektedir. $\mathrm{Bu}$ konu ile ilgili yapılan çalışmalar incelendiğinde; ventilatör ile ilişkili pnömoni (VIP), nazogastrik tüp ile beslenen hastalarda ise aspirasyon riskini azaltmak için sıklıkla semifawler pozisyonun tercih edildiği belirtilmektedir (Clini ve Ambrosino 2005; Sierra, Benitez, Leon and Rello 2005). Benzer şekilde Alexiou, Ierodiakonou, Dimopoulos ve Falagas (2009)'ın randomize kontrollü çalışmalardan derledikleri meta analiz sonucunda semifawler pozisyonun uygulamasinın kolay ve ventilasyon desteği olan hastalar için VİP riskini azaltmada güvenli bir pozisyon olduğu sonucuna varılmıştır. Heyland ve ark. (2002)'nın çalışmasında 
da, hastaların VIP riskini azaltmak için \%54'üne 3463 derece değişen aralıklarda fawler yatış pozisyonu verildiği belirtilmektedir.

$\mathrm{Bu}$ araştırma sonuçlarına göre pozisyonların verilmesi sırasında hemşire; vücut mekaniği ilkelerine uymalı, verilecek pozisyona bireyin durumuna göre karar vermeli ve en az 1-2 saat ara ile dönüşümlü pozisyon değişimini gerçekleştirmelidir. Bununla birlikte; basınç bölgeleri yardımcı araçlarla (yastık, trokanter rulo vb.) desteklenerek deri ve kas-iskelet sistemi yaralanmalar1 önlenmelidir (İnce 2006; Tritak 2009).

\section{Yoğun Bakım Ünitelerinde Güvenli Hasta Egzersizi}

Hastanın duyusal algı durumu ve uyumu iyi olduğunda, kendisi pozisyonunu değiştirebilmekte, hareketini sağlayabilmektedir. Ancak bilinç durumunda değişim, omurilik yaralanması, motor ve duyusal fonksiyonların yokluğu ve pozisyon değişiminin mümkün olmaması gibi durumlarda pozisyon değişimi kadar hareketliliğin sağlanması da önem taşımaktadır (Şendir ve ark. 2012; Karadă̆ 2003). Perme ve Chandrashekar (2009) yoğun bakım ünitelerinde kesin yatak istirahatinde yatan hastalarda bir haftanın sonunda kas gücünün $\% 20$ 'sinin kaybedildiği ve devam eden her hafta için \%20 'ye kadar kas gücü kaybının olduğu belirtmektedir. Bununla birlikte kas kayıpları ve nörolojik defisitler ortaya çıkmaktadır. Literatürde, bu olumsuz sonuçların önlenmesinde, erken aşamalı mobilizasyon ve egzersizlerin önemi vurgulanmaktadır (Clark ve ark. 2013; Dammeyer ve ark. 2013; King 2012). Güçsüzlük duru$\mathrm{mu}$, hemodinamik göstergeleri de olumsuz düzeyde etkilediği için kas gücünü geliştirecek egzersizlerin yanı sıra solunum egzersizleri de uygulanmalıdır.

Fiziksel egzersize başlamadan önce sağlık bakımı ekibi üyeleri ile işbirliği yapılarak, hastanın fiziksel, duyusal ve mental durumu tanılanarak, yapılacak olan egzersiz türüne karar verilmelidir. Yoğun bakım ünitelerinde yatan hastalarda öncelikli olarak yatak içinde aktif ve pasif hareketlere odaklanılmalıdır. Uygulama öncesi, süresi ve sonrasındaki yaşam bulguları, hastanın işbirliği düzeyi değerlendirilmelidir. Hastanın durumuna göre öncelikli olarak Eklem Hareket Açık- lığ1 (EHA) (açma, kapama, kendi etrafında döndürme, yaklaştırma, uzaklaştırma vb.) uygulanmalıdır. $\mathrm{Bu}$ egzersizler her bir ekstremite için özellikle izometrik ve izokinetik egzersizleri bir arada içermelidir. Egzersizler sirasinda ekstremiteler alttan tutularak desteklenmeli, eklem zorlanmamalı ve yaşam bulgularında değişim, ağrı olduğunda ara verilmeli veya sonland1rılmalıdır. Daha sonra yapılan odaklanmış tanılama ile hastanın bilinç, güç, hareket kısıtlılığ 1 varlığ 1 vb. durumu göz önünde bulundurularak erken mobilizasyon konusunda desteklenmelidir (Clini ve Ambrosino 2005; Needham 2008; Perme ve Chandrashekar 2009). Ayrica fiziksel egzersizler kadar uygulanacak olan solunum egzersizlerinin de hareketsizliğe bağlı solunum komplikasyonlarını önemli ölçüde azalttığg belirtilmektedir. Sağlık bakımı ekibi üyeleri hastanın durumunu değerlendirerek uygulanacak olan solunum egzersizleri türüne karar vermelidir (İnce 2006). Hastaya uygulanacak egzersizler ve izlenmesi gereken adımlar Tablo 1'de özetlenmiştir.

\section{Yoğun Bakım Ünitelerinde Erken Mobilizasyon}

Güncel yaklaşımlar geleneksel yoğun bakım uygulamalarının aksine hastaların en az sedasyon ile ya da mümkün ise sedasyon kullanılmadan, erken dönemde rehabilitasyon uygulamalarına yönelmiştir (Latronico ve Rasulo 2010). Bu yaklaşımın yerine getirilmesinde yoğun bakım hemşireleri, sağlık bakım ekibi üyeleri arasında anahtar rol üstlenir. Hasta ile iletişimin gerçekleştirilmesi, ağrının kontrol altına alınması, bireyin aktivite düzeyinin tanılanması, egzersizlere ve yürümeye cesaretlendirmesi önemli hemşirelik girişimlerindendir (Vincent ve Norrenberg 2009). Konu ile ilişkili yapılan çalışmalarda, bu girişimlerin sürdürülmesinde aşamalı erken mobilizasyon rehberlerinin klinik uygulamalarına uyumlaştırılması ve ekip işbirliği ile uygulanmasının önemi vurgulanmıştır (Dammayer ve ark. 2013; Harris ve Shahid 2014; King 2012). Morris ve ark. (2008) mobilite programı kullanılarak uygulanan erken fiziksel terapinin kolay ve etkili olduğunu, yoğun bakım ünitesinde ve hastanede kalış süresini kısalttığını saptamıştır. Tablo 2'de örnek bir aşamalı mobilizasyon programının girişim aşamalarına yer verilmiştir. 
Tablo 1. Hastaya Uygulanacak Egzersizlerde İzlenmesi Gereken Adimlar

\begin{tabular}{|c|c|}
\hline Girişim & İzlenmesi Gereken Adımlar \\
\hline Eğitim & $\begin{array}{l}\text { Hasta ve ailesine pozisyon } \\
\text { değişimi, egzersiz ve erken } \\
\text { mobilizasyonun önemine ilişkin } \\
\text { eğitim verilmeli }\end{array}$ \\
\hline Pozisyon değiştirme & $\begin{array}{l}\text { Özellikle basınç noktalarını sık } \\
\text { aralıklarla gözlemleme } \\
\text { Hastanın durumuna göre pozisyon } \\
\text { değişimini planlama (örn. } \\
\text { ortopedi, nörolojik sorunları } \\
\text { dikkate alma) }\end{array}$ \\
\hline Yatak içi egzersizler & $\begin{array}{l}\text { Birbiri ile geçişi kolay olan } \\
\text { pozisyonları verme (supine } \\
\text { pozisyonu sonrası yatak içinde } \\
\text { oturma vb.) } \\
\text { Yatak içinde oturma sırasında } \\
\text { sırasıyla; } \\
\text { *EHA, } \\
\text { *solunum egzersizleri, } \\
\text { *denge/koordinasyonu sağlama } \\
\text { egzersizleri, } \\
\text { *öz-bakım aktiviteleri, } \\
\text { *yatak içinde yardımsı oturma }\end{array}$ \\
\hline Yatak dişına transfer & $\begin{array}{l}\text { Öncelikli olarak tam yardım ile } \\
\text { tekerlekli sandalyeye oturtma } \\
\text { Gerekli yardımı sağlayarak } \\
\text { tekerlekli sandalyeye oturtma ve } \\
\text { walker desteği ile ayağa kalkma }\end{array}$ \\
\hline Yürüme programı & $\begin{array}{l}\text { Hastanın walker yardımı ile ayağa } \\
\text { kalkabilmesi ve adım atabilmesi }\end{array}$ \\
\hline Fiziksel egzersiz & $\begin{array}{l}\text { Bir ya da birkaçı bir arada } \\
\text { kullanılabilir: } \\
\text { *pasif EHA, } \\
\text { *yardım edilerek aktif EHA, } \\
\text { *kas gücünü artıran egzersizleri } \\
\text { uygulama (ayak tabanları ile } \\
\text { itme, hafif ağırlık ( } 0,45-2,25 \mathrm{~kg} \text {.) } \\
\text { kaldırma, egzersiz bandını çekme } \\
\text { vb.), } \\
\text { *solunum egzersizleri (derin } \\
\text { solunum, öksürme, spirometre } \\
\text { çalışması vb.). }\end{array}$ \\
\hline Egzersiz süresi & $\begin{array}{l}\text { Hastanın tolere edebildiği ölçüde } \\
15-30 \mathrm{dk} \text {. ile sınırlandırılmalı. }\end{array}$ \\
\hline Egzersiz s1klığ & $\begin{array}{l}\text { İlk hafta günde } 1 \mathrm{kez}, \\
\text { Sonrasinda günde en az } 2 \mathrm{kez} \\
\text { uygulanmalı. }\end{array}$ \\
\hline
\end{tabular}

Kaynak: Perme, C., Chandrashekar, R. (2009). Early mobility and walking program for patients in intensive care units: Creating a standard of care. American Journal of Critical Care, 18(3): 212-221.
Tablo 2. Aşamalı Mobilizasyon Girişimleri

\begin{tabular}{|c|c|}
\hline Düzey & Girişim \\
\hline Düzey 0 & $\begin{array}{ll}- & 2 \text { saatte bir pozisyon değişimi uygulanır } \\
\text { - } & \text { Pasif EHA egzersizleri (3 kez/ gün, } 10 \\
& \text { tekrar) uygulanır } \\
\text { - } & \text { Baş } 30-45^{\circ} \text { yükseltilir. } \\
\text { - } & \text { FiO2 }>\% 60 \text { ise lateral rotasyon } \\
& \text { sürdürülür }\end{array}$ \\
\hline Düzey 1 & $\begin{array}{ll}\text { - } & 2 \text { saatte bir pozisyon değişimi uygulanır } \\
\text { - } & \text { Aktif ya da pasif EHA egzersizleri (3 } \\
& \text { kez/ gün, } 10 \text { tekrar) uygulanır } \\
\text { - } & \text { Baş } 30-45^{\circ} \text { yükseltilir. } \\
\text { - } & \text { FiO2 }>\% 60 \text { ise lateral rotasyon } \\
& \text { sürdürülür } \\
\text { - } & \text { Yatakta/yatakdışında oturtulur( } 3 \mathrm{kez} / \text { gün }) \\
\text { - } & \text { Ayakları yatak kenarında sarkıtılır(3 kez/ } \\
\text { gün) }\end{array}$ \\
\hline Düzey 2 & $\begin{array}{ll}\text { - } & 2 \text { saatte bir pozisyon değişimi uygulanır } \\
\text { - } & \text { Aktif ya da pasif EHA egzersizleri (3 } \\
& \text { kez/ gün, } 10 \text { tekrar) uygulanır } \\
\text { - } & \text { Baş } 30-45^{\circ} \text { yükseltilir. } \\
\text { - } & \text { FiO2 }>\% 60 \text { ise lateral rotasyon } \\
& \text { sürdürülür } \\
\text { - } & \text { Yataktan kaldırılarak sandalyeye } \\
& \text { oturtulur( } 3 \mathrm{kez} / \text { gün) } \\
\text { - } & \text { Ayakta durma (3 kez/ gün) } \\
\text { - } & \text { Yürüme }(3 \mathrm{kez} / \text { gün })\end{array}$ \\
\hline
\end{tabular}

Kaynak: Dammeyer, J. A. ve ark. (2013). Mobilizing outcomes implementation of a nurse-led multidisciplinary mobility program. Critical Care Nursing Quality, 36(1): 109-119.

\section{SONUÇ VE ÖNERILER}

$\mathrm{Bu}$ makale yoğun bakım ünitelerinde sıklıkla uygulanan koruyucu hasta pozisyonları, egzersizleri ve erken aşamalı mobilizasyona ilişkin anahtar noktaları, literatür sonuçlarını ve uygulama örneğini içermektedir. Sonuç olarak, yoğun bakım ünitesinde yatan her bir hasta tanilanmal1, egzersiz, koruyucu pozisyon verme ve mobilizasyon programı oluşturulmalı ve uygulanmalıdır. $\mathrm{Bu}$ uygulamaları gerçekleştirirken, hastanın bireysel özelliklerine, alışkanlıklarına, tercihlerine ve hastalık durumuna özen gösterilmesi oldukça önemlidir. Uygulama sonunda hemşirelik bakım planında belirlenen beklenen hasta sonuçlarına göre değerlendirme yapılmalıdır.

Ayrıca bu girişimleri uygulayan hemşirenin de kendi sağlığını koruma adına vücut mekaniği ilkelerini bilmesi ve uygulaması önem taşımaktadır. 


\section{KAYNAKLAR}

Acaroğlu, R. (2011). Sağlık öyküsü ve fiziksel muayene. Atabek Aştı, T. Karadağ, A. (Eds). Klinik Uygulama Yöntemleri ve Becerileri. Nobel Tıp Kitapevi, Adana, 539-609.

Alexiou, G. V., Ierodiakonou, V., Dimopoulos, G., Falagas, M. (2009). Impact of patient position on the incidence of ventilatorassociated pneumonia: A meta-analysis of randomized controlled trials. Journal of Critical Care, 24(4): 515-522.

Banasik, J. L., Emerson, R. J. (2001). Effect of lateral positions on tissue oxygenation in the critically ill. Washington State University College of Nursing, 30(4): 269-276.

Beğer, T. (2004). Yoğun bakımda dekibüt ülserleri-risk faktörleri ve önlenmesi. Yoğun Bakım Dergisi, 4(4): 244-253.

Bloomfield, R., Noble, D. W., Webster, N. R. (2009). Prone position for acute respiratory failure in adults. Cochrane Database of Systematic Reviews, 4.

Clark, D. E., Lowman, J. D., Griffin, R. L., Matthews, H. M., Reiff, D. A. (2013). Effectiveness of an early mobilization protocol in a trauma and burns intensive care unit: A retrospective cohort study. Physical Therapy, 93: 186-196.

Clini, E., Ambrosino, N. (2005). Early physiotherapy in the respiratory intensive care unit. Respiratory Medicine, 99(9): 1096-1104.

Dammeyer, J. A. ve ark. (2013). Mobilizing outcomes implementation of a nurse-led multidisciplinary mobility program. Critical Care Nursing Quality, 36(1): 109-119.

Dillon, P. M. (2007). Nursing Health Assessment- A Critical Thinking, Case Studies Approach. 2th. ed., Davis Company, Philadelphia.

Fan, E., Zanni, J. M., Dennison, C. R., Lepre, S. J., Needham, D. M. (2009). Critical illness neuromyopathy and muscle weakness in patients in the intensive care unit. AACN Advanced Critical Care, 20(3): 243-253.

Harris, C. L, Shahid, S. (2014). Physical therapy-driven quality improvement to promote early mobility in the intensive care unit. Proc (Bayl Univ Med Cent), 27(3): 203-207.

Heyland, D. K., Cook, D. J., Dodek, P. M. (2002). Prevention of ventilator-associated pneumonia: Current practice in Canadian Critical Care Units. Journal of Critical Care, 17(3): 161-167.

İnce, D. İ. (2006). Yoğun bakım ünitesinde solunum tedavisi. Yoğun Bakım Dergisi, 6(1): 28-42.

Karadağ, A. (2003). Basınç ülserleri: değerlendirme, önleme ve tedavi. C.Ü. Hemşirelik Yüksekokulu Dergisi, 7(2): 41-48.

Korkut, H. (2011). Vücut mekanikleri, taşıma ve pozisyon verme. Atabek Aşt1, T. Karadağ, A. (Eds). Klinik Uygulama Yöntemleri ve Becerileri. Nobel Tip Kitapevi, Adana, 224-301.
King, L. (2012). Developing a progressive mobility activity protocol. Ortopaedic Nursing, 31(5): 253-262.

Kuyurtar, F. (2010). Hastalara verilen pozisyonun oksijenlenmeye etkisi. Firat Sağllk Hizmetleri Dergisi, 5(14): 15-24.

Latronico, N., Rasulo, F. A. (2010). Presentation and management of ICU myopathy and neuropathy. Current Opinion Critical Care, 16(2): 123-127.

Morris, P. E. (2007). Moving our critically ill patients: Mobility barriers and benefits. Critical Care Clinics, 23(1): 1-20.

Morris, P. E. ve ark. (2008). Early intensive care unit mobility therapy in the treatment of acute respiratory failure. Critical Care Medicine, 36(8): 2238-2243.

Needham, D. M. (2008). Mobilizing patients in the intensive care unit improving neuromuscular weakness and physical function. JAMA, 300(14): 1685-1690.

Perme, C., Chandrashekar, R. (2009). Early mobility and walking program for patients in intensive care units: Creating a standard of care. American Journal of Critical Care, 18(3): 212-221.

Sierra, R., Benitez, E., Leon, C., Rello, J. (2005). Prevention and diagnosis of ventilator-associated pneumonia: A survey on current practice in Southern Spanish. Chest, 128(3): 1667-1773.

Şendir, M. (2005). Basınç yaralarının önlenmesi ve bakımı. Hemşirelik Dergisi, 13(54): 53-64.

Şendir, M., Büyükyılmaz, F., Aktaş, A. (2012). Doku bütünlüğünün sağlanması ve yara bakımı. Atabek Aștı, T. Karadağ, A. (Eds). Klinik Uygulama Yöntemleri ve Becerileri. Nobel Tıp Kitapevi, Adana, 487-535.

Thomas, P. J., Paratz, J. D., Pilmann, J., Stanton, W. R. (2007). Lateral positioning of ventilated intensive care patients: A study of oxygenation, respiratory mechanics, hemodynamics, and adverse events. Heart \& Lung: The Journal of Critical Care 36(4): 277-286.

Tonyoo, S., Vilaichone, W., Permpikul, C. (2006). The effect of lateral position on oxygenation in ARDS Patients: A pilot study. Journal of Medical Association Thai, 89(5): 55-61.

Tritak, A. (2009). Mobility and immobility. Potter, P. A, Perry, A. G. (Eds). Fundamental of Nursing. 7th. ed., Mosby Elseiver, St. Louis, 1219-1228.

Vincent, J. L, Norranberg, M. (2009). Intensive care unit-acquired weakness: Framing the topic. Critical Care Medicine, 37(10): 296-298.

Winlekman, C. (2000). Effect of backrest position on intracranial and cerebral perfusion pressures in traumatically brain-injured adults. American Journal of Critical Care, 9(6): 373-380.

Yıldırım, G. Ö, Yavuz, M. (2009). Yoğun bakımlarda hastalara verilen sırtüstü pozisyonların hemodinamik ve fizyolojik ölçümlere olan etkileri. Maltepe Üniversitesi Hemşirelik Bilim ve Sanatı Dergisi, 2(2): 94-99. 